\title{
Can green policies be trusted and will they lead to practical results? Evidence from the U.S. electric power sector
}

\author{
Ardalan Irani ${ }^{1}$, Zahra Tavassoli Hojati ${ }^{1}$ and S.F.Ghaderi* ${ }^{1,2}$ \\ ${ }^{1}$ Department of Industrial Engineering, College of Engineering, \\ University of Tehran \\ Karegar Shomali Street, Tehran (Iran) \\ Phone number:+0098 21 88021067, Fax: +0098 21 88013102, e-mail: irani.ardalan@ut.ac.ir, ghaderi@ut.ac.ir \\ ${ }^{2}$ Research Institute of Energy Management and Planning (RIEMP) \\ Ghods Street, Enghelab Avenue, Tehran (Iran) \\ Phone: +0098 21 66980830, Fax: +0098 21 66461680, e-mail: riemp.training@ut.ac.ir
}

\begin{abstract}
From Kyoto to Paris, treaties and protocols have been devised and ratified unanimously in order to prevent the well-known phenomenon "climate change". But has global warming been practically deferred or prevented? If so, then why should we experience warmer seasons each year or even behold water level rise due to the melting of arctic ice mountains? These are serious questions that could expose the future of green energies and green policies to jeopardy, if not answered to scientifically. Hence, we decided to provide a proof to clarify whether the practice of green policies could lead to actual results or the enacted protocols and policies are just fantasies. As a case, the U.S. electricity sector was selected and by providing an econometric framework, the dynamics between the carbon dioxide and coal as the main culprit of global warming and total amount of exploited renewable energy in power generation was studied.
\end{abstract}

\section{Keywords}

$\mathrm{CO}_{2}$ emissions, US electricity sector, coal, renewable energies, green policies.

\section{Introduction}

Until a few years ago, people just used to hear about environmental decay and global warming in the news or read about them in scientific magazines. Once in a blue moon, symposiums on those issues were held where scientists kept emphasizing the necessity of wiser selection of energy mix and exigency of adopting green policies in order to prevent the increase of the global temperature from exceeding two ${ }^{\circ} \mathrm{C}$; But since the effects were gradual and they had just begun, none of those recommendations were taken seriously specially by politicians and policy makers. Now, those gradual effects have accumulated and raised the alarm for all people of the word. The climate change has driven the lives of hundreds of millions of human beings to the utmost of plight and has proven itself to be serious and really evident. Therefore, practical solutions are to be devised and come into force in before this menacing monster could risk the life of this planet along with all of its residents. This article tries to prove that science cannot be defied and that we have to bequeath our hope for survival to it.

The United States of America is the second biggest emitter of carbon dioxide in the world; The country's energy-related $\mathrm{CO}_{2}$ emissions was 5,171 million metric tons in 2016. A considerable portion of this amount, 35\% or 1821 million metric tons, was emitted by the country's electric power sector. Among all of the pollutant fuels, coal is the main culprit accounting for 1241 million metric tons of the carbon dioxide emitted by the country's electric power sector. (https://www.eia.gov)

The former government of the U.S. adopted green policies in its energy sector since the very first days of taking the office until the waning months. For instance, Paris Climate Agreement that could be considered as the masterpiece of President Obama's environmental policies, was achieved and enforced just before him leaving the office. "In addition to the Clean Power Plan, the Obama administration made other substantial strides to boost the viability and use of clean and renewable energy technologies in the United States. The American Recovery and Reinvestment Act (AKA Stimuus Package), one of President Obama's first acts as President, was enacted in response to the Great Recession of 2007-2009. However, one of the most substantial components of the act was nearly $\$ 90$ billion of investment in energy infrastructure, energy efficiency and renewable energy research and investment, and transportation. Particular investments included designated appropriations for public transportation systems, increasing energy efficiency in federal buildings, and direct financial support for the renewable energy industry." (http://www.hmc.edu) 
Figure 1, depicts the amount of $\mathrm{CO}_{2}$ emitted by the U.S. electric power sector in million metric tons and the amount of renewable energies (including hydroelectric power, geothermal energy, solar energy, wind energy and biomass energy) exploitation by that sector in trillion Btu in the period between 1949 to 2016. As it could be obviously beheld and understood from the figure, the orientations of both variables show us a drastic change after 2008, since the democratic government took the office.

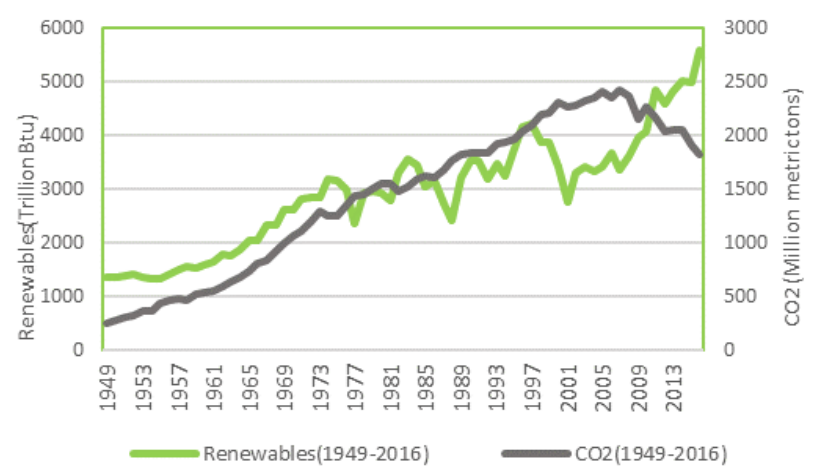

Fig. 1. $\mathrm{CO}_{2}$ emitted by the electricity sector VS. renewable energies exploitation

There is one vital question about Figure 1 which is quite worth mentioning; where would the $\mathrm{CO}_{2}$ emissions stood by now, if those investments in renewable energies were not made and those policies were not devised and adopted?

As it is mentioned, coal accounts for 1241 million metric tons of $\mathrm{CO}_{2}$ emission by the U.S. electricity sector which is $68 \%$ of the total carbon dioxide emitted by that sector. Figure 2 depicts the carbon utilization versus the renewable energies utilization for the purpose of electricity generation in trillion Btu. As it could be easily observed in Figure 2, the fall in coal utilization in power plants for electricity generation is considerable that is also another result of those green policies.

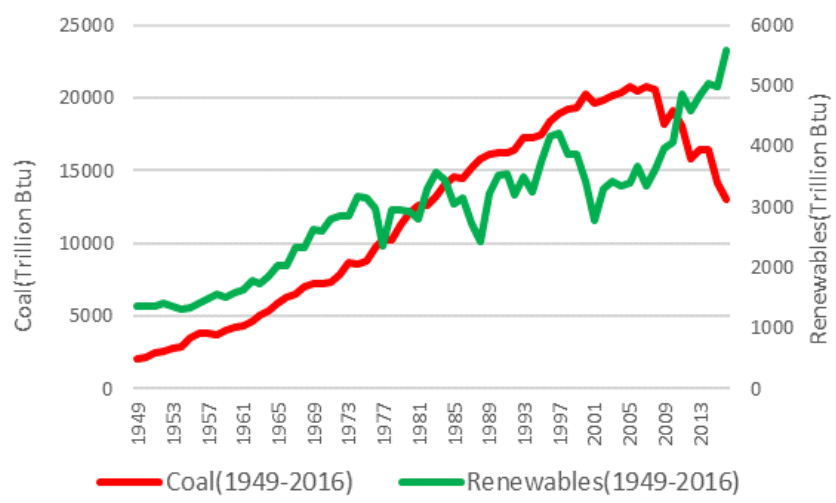

Fig. 2. Total coal utilization VS. total renewable energies utilization
Figure 3 evidently demonstrates us the inversion of trend in $\mathrm{CO}_{2}$ emission by the electricity power sector and renewable energies utilization in a scatter plot.

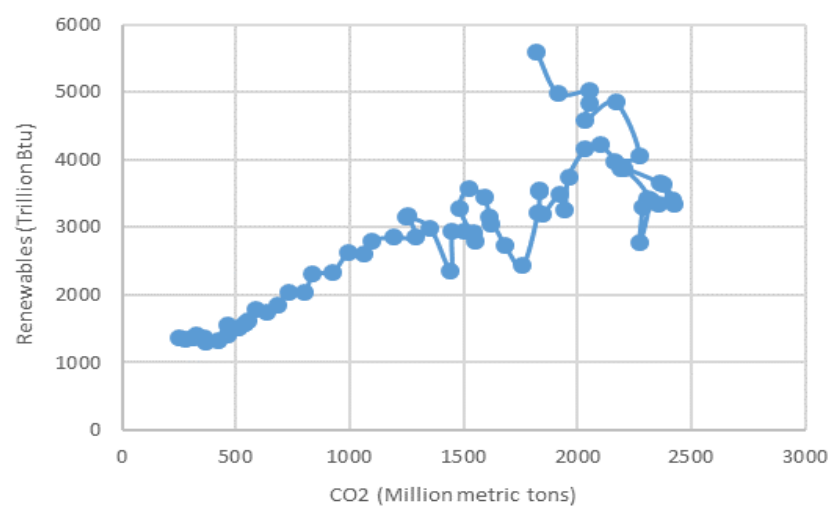

Fig. 3. Trend of $\mathrm{CO}_{2}$ emissions and renewable energies utilization by the U.S. electricity sector (1949-2016)

After the 2016 presidential election of the United States and a little while after the commencement of the new administration, it became evident that the U.S. intends not to abide by the Paris Climate Agreement any longer. This withdrawal became an apt and sufficient incentive to investigate the efficiency of the energy policies of the previous government of the U.S. and a good pretext to clear the air for those who doubted those policies.

Exploring the literature, there are lots of articles that have investigated the dynamics and nexus between issues such as $\mathrm{CO}_{2}$ emissions and economic growth, energy consumption and $\mathrm{CO}_{2}$ emissions, etcetera; the studies can generally be categorized in three different groups; firstly: those that investigate economic ramifications of green policies, secondly those that study environmental effects of energy consumption and finally those that practice the stipulation of energy policies.

Many of the studies in the gamut of "energy demandcarbon dioxide emissions nexus" do not consider energy prices as a major protagonist in energy demand scenario and thereby emissions. Jaforullah and king [1] have involved this factor in their study with the objective of comparing renewable energies with nuclear energy and the results show that the usage of renewables would negatively affect $\mathrm{CO}_{2}$ emissions and it is more efficient than the policy of investing in nuclear energy. These findings, however, contradict the previous outcomes of other studies. Chakravarty and Tavoni [2] have tried to shed light on energy consumption and its impacts on pollutant emissions mitigation in the horizon of 2030 . Using a statistical model, the authors have mapped global energy consumption and have come to the conclusion that meeting the energy poverty eradication policy by 2030, the global temperature would raise by $0.13{ }^{\circ} \mathrm{C}$. Using data envelopment approach, Chen and Geng [3] investigated 30 countries which are the main emitters of carbon dioxide; They've included renewable energy as one of the inputs and GDP and $\mathrm{CO}_{2}$ as desirable and undesirable outputs. The authors did not find a significant 
correlation between the proportion of renewable energy consumption and fossil fuel saving and $\mathrm{CO}_{2}$ emission reduction. Ben Jebli and Ben Youssef [4] have exerted panel co-integration techniques and Granger Causality tests in order to study whether there is a dynamic causal relation among per capita energy consumption, agricultural value added, $\mathrm{CO}_{2}$ emissions and GDP or not; Exploiting the data for the period between 1980-2011, the results indicate that in the long-run, an increase in agricultural value added would lead to a plunge in $\mathrm{CO}_{2}$ emissions in the north African countries. Aliprandi et al. [5] have tried to provide a framework which by considering actual conditions of electricity market in Italy, simulates the technical constraints of power plants and thereby estimates Carbon dioxide emissions under different scenarios involving renewable sources. De Arce et al. [6] have tried to determine the policy that would help dealing with the emissions issue more efficiently than other solutions. In other words, the one policy that incentivizes the exploitation of renewable energies the most. Investigating options to mitigate climate change, Alberini et al. [7] have used a mathematical model in order to quantify Italian and Czech households' tendency to pay for possible options of climate change mitigation, each of which implemented by different regulations and given their own incentives.

\section{Method and Approach}

All of those three figures that were presented in the introduction section, explain the drastic change resulted by the adoption of green policies; But before concluding that the policies are efficient and trustworthy, a mathematical approach is required. In connection with the aforementioned guideline, it must be primarily proved mathematically that there is a correlation among the $\mathrm{CO}_{2}$ emissions from the electric power sector as the dependent variable and the amount of coal and renewable energies utilization by that sector as the principal pollutant fuel and the solution of the problem respectively, as independent variables; Hence, an econometric framework was provided in order to study the dynamics among the variables. Equation 1 explains the primary model.

$$
\mathrm{CO}_{2 \mathrm{t}}=\beta_{1} \mathrm{C}_{\mathrm{t}}+\beta_{2} \mathrm{R}_{\mathrm{t}}+\mathrm{e}_{\mathrm{t}}
$$

where $\mathrm{CO}_{2 \mathrm{t}}$ represents the $\mathrm{CO}_{2}$ emissions by the electricity sector and $\mathrm{C}_{\mathrm{t}}$ and $\mathrm{R}_{\mathrm{t}}$ represent the amount of coal and renewable energies exploitation respectively. Table I describes the variables in detail.
Table I- Definition of variables in equation (1)

\begin{tabular}{|c|c|c|c|}
\hline Variables & Definition & $\begin{array}{c}\text { Unit of } \\
\text { measurement }\end{array}$ & $\begin{array}{c}\text { Data } \\
\text { source }\end{array}$ \\
\hline $\mathrm{CO}_{2 \mathrm{t}}$ & $\begin{array}{l}\text { Total carbon dioxide } \\
\text { emissions from the } \\
\text { U.S. electricity power } \\
\text { sector }\end{array}$ & $\begin{array}{l}\text { Million } \\
\text { metric tons }\end{array}$ & EIA \\
\hline$C_{t}$ & $\begin{array}{l}\text { Total amount of coal } \\
\text { utilization by the U.S. } \\
\text { electricity power } \\
\text { sector }\end{array}$ & Trillion Btu & EIA \\
\hline $\mathbf{R}_{\mathbf{t}}$ & $\begin{array}{l}\text { Total amount of } \\
\text { renewable energies } \\
\text { exploitation(including } \\
\text { hydroelectric power, } \\
\text { geothermal energy, } \\
\text { solar energy, wind } \\
\text { energy and biomass } \\
\text { energy) }\end{array}$ & Trillion Btu & EIA \\
\hline
\end{tabular}

Before applying data into the model, it must be verified that all sets of data are stationary; performing the unit root test, it became evident that all three data sets are stationary at second difference. Hence, the second difference of each variable is applied into the model. The data is acquired from the Energy Information Administration of the United States (EIA).

Running the primary econometric model (Equation (1)) with the aforementioned variables, it is found out that there is a major defect in the model which is serial autocorrelation among the residuals. The problem could be solved by entering lags of different variables in the model; This could indicate that the regression model, should be an auto-regressive one. Applying the solution, it became evident that the problem could be solved by entering two lags of each variable; but not all the two lags of all variables were meaningful. The final model after all those steps, is written down here as Equation (2).

$$
\mathrm{CO}_{2 \mathrm{t}}=\beta_{1} \mathrm{C}_{\mathrm{t}}+\beta_{2} \mathrm{R}_{\mathrm{t}}+\beta_{3} \mathrm{C}_{\mathrm{t}}(-1)+\beta_{4} \mathrm{C}_{\mathrm{t}}(-2)+\beta_{5} \mathrm{CO}_{2 \mathrm{t}}(-1)+\mathrm{e}_{\mathrm{t}}
$$

where $\mathrm{CO}_{2 \mathrm{t}}$ represents the $\mathrm{CO}_{2}$ emissions from the electricity sector in the year $t, C_{t}$ and $R_{t}$ represent the amount of coal and renewable energies utilization by the electricity sector respectively, $C_{t}(-1)$ and $C_{t}(-2)$ are the first and second lags of $\mathrm{C}_{t}$ respectively and $\mathrm{CO}_{2 \mathrm{t}}(-1)$ represents the first lag of $\mathrm{CO}_{2 \mathrm{t}} . \beta_{1}$ to $\beta_{5}$ are the coefficients of the variables of Equation (2) respectively.

\section{Results}

After running the final model (Equation (2)) on "EViews 9 " software, the key characteristics of the model alluded the desirability of the auto-regressive model. The results are reported in Table II: 
Table II- Results of the model

\begin{tabular}{cccc}
\hline Variables & Coefficient & Std. Error & Prob. \\
\hline $\mathbf{C}_{\mathbf{t}}$ & 0.101948 & 0.006 & 0.0000 \\
$\mathbf{C}_{\mathbf{t}}(-\mathbf{1})$ & 0.041082 & 0.009979 & 0.0001 \\
$\mathbf{C}_{\mathbf{t}}(-\mathbf{2})$ & 0.028023 & 0.006478 & 0.0001 \\
$\mathbf{R}_{\mathbf{t}}$ & -0.020709 & 0.007473 & 0.0075 \\
$\mathbf{C O}_{\mathbf{2 t}}(-\mathbf{1})$ & -0.281224 & 0.099698 & 0.0065 \\
\hline
\end{tabular}

Table II indicates that in 5 percent level of significance, all of the variables are meaningful inside the model. The positive coefficients of coal $\left(\beta_{1}, \beta_{3}\right.$ and $\left.\beta_{4}\right)$ and the negative coefficient of renewables $\left(\beta_{2}\right)$ indicate the way those variables are affecting the $\mathrm{CO}_{2}$ emission by the U.S. electric power sector. In addition to the p-value that determines the significance of a variable inside the model, there is the pillar " $\mathrm{R}$ " " value of the model indicating that how well the model is fitted. Table III shows us the amount of " $\mathrm{R}$ " " and also " $\mathrm{R} 2$ adjusted" of the fitted model.

Table III- "R-squared" and "R-squared adjusted" values of the model

\begin{tabular}{ll}
\hline R-squared & 0.915053 \\
R-squared adjusted & 0.909294 \\
\hline
\end{tabular}

Table III proves that variables are chosen correctly and that independent variables are actually affecting the dependent variable. But before the model could be fully trusted, the residuals diagnostic tests (Normality test, Heteroskedasticity test and serial correlation LM test) should be performed. Fortunately, the aforementioned tests were performed and the model passed them successfully; This would imply the flawlessness of the fitted auto-regressive model. For instance, Figure 4 demonstrates the result of performing the normality test and Table IV explains the results of performing the heteroscedasticity test.

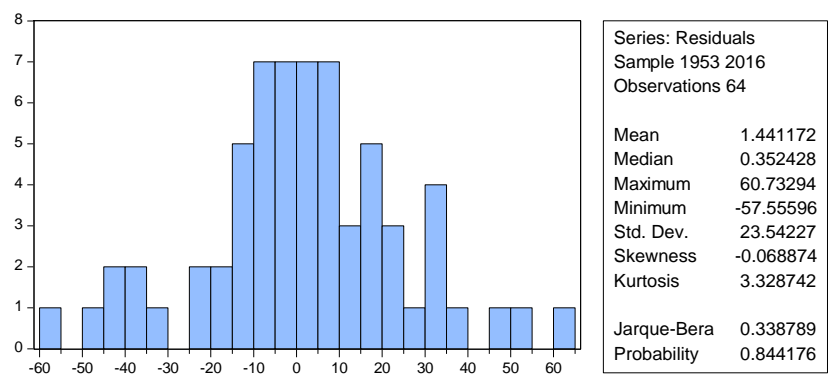

Fig. 4. Histogram normality test

Table IV- Heteroskedasticity Test: Breusch-Pagan-Godfrey

\begin{tabular}{cccc}
\hline \hline F-statistic & 1.123626 & Prob. F(5,58) & 0.3581 \\
Obs*R-squared & 5.651852 & Prob. Chi-Square(5) & 0.3416 \\
Scaled explained SS & 5.546201 & Prob. Chi-Square(5) & 0.3529 \\
\hline \hline
\end{tabular}

\section{Conclusion}

There are multitudes of proofs indicating the urgency of global warming and climate change. Although those phenomena are well-known and well-spoken in today's world, some decisions of politicians and policy makers convey the unimportance of those phenomena to them. This research, takes the smallest step to provide an analytical and mathematical evidence, that "climate change" issue is not a fantasy and could endanger the lives of all human beings if not taken seriously. After all these explanations and model-buildings, it is now feasible to answer the main question and the title of the paper; Yes, green policies would yield tangible results if adopted and implemented wisely. If environmental issues keep to be overlooked like before and policy makers do not consider environmental ramifications of their decisions, global warming would definitely exceed 2 degrees.

\section{Acknowledgement}

We sincerely thank Mr. Curley Andrews of the energy information administration of the U.S. for his benign cooperation in helping us acquiring the appropriate data.

\section{References}

[1]. Jaforullah, M. and A. King, Does the use of renewable energy sources mitigate $\mathrm{CO} 2$ emissions? A reassessment of the US evidence. Energy Economics, 2015. 49: p. 711-717.

[2]. Chakravarty, S. and M. Tavoni, Energy poverty alleviation and climate change mitigation: Is there a trade off? Energy economics, 2013. 40: p. S67-S73.

[3] . Chen, W. and W. Geng, Fossil energy saving and $\mathrm{CO} 2$ emissions reduction performance, and dynamic change in performance considering renewable energy input. Energy, 2017. 120: p. 283-292.

[4] . Mehdi, B.J. and B.Y. Slim, The role of renewable energy and agriculture in reducing $\mathrm{CO} 2$ emissions: Evidence for North Africa countries. Ecological Indicators, 2017. 74: p. 295-301.

[5]. Aliprandi, F., A. Stoppato, and A. Mirandola, Estimating $\mathrm{CO} 2$ emissions reduction from renewable energy use in Italy. Renewable Energy, 2016. 96: p. 220232 .

[6] . de Arce, M.P., E. Sauma, and J. Contreras, Renewable energy policy performance in reducing $\mathrm{CO} 2$ emissions. Energy Economics, 2016. 54: p. 272-280.

[7] . Alberini, A., et al., Preferences for Energy Efficiency vs. Renewables: What Is the Willingness to Pay to Reduce CO 2 Emissions? Ecological Economics, 2018. 144: p. 171-185. 